Marquette University

e-Publications@Marquette

College of Nursing Faculty Research and

Publications

Nursing, College of

$11-2010$

\title{
Technology-Enhanced Practice for Patients with Chronic Cardiac Disease: Home Implementation and Evaluation
}

\author{
Patricia Flatley Brennan \\ University of Wisconsin - Madison \\ Gail Casper \\ University of Wisconsin - Madison \\ Laura Burke \\ Aurora Healthcare \\ Kathy Johnson \\ University of Wisconsin - Madison \\ Roger L. Brown \\ University of Wisconsin - Madison
}

See next page for additional authors

Follow this and additional works at: https://epublications.marquette.edu/nursing_fac

Part of the Nursing Commons

\section{Recommended Citation}

Flatley Brennan, Patricia; Casper, Gail; Burke, Laura; Johnson, Kathy; Brown, Roger L.; Valdez, Rupa; Sebern, Margaret; Perez, Oscar; and Sturgeon, Billie, "Technology-Enhanced Practice for Patients with Chronic Cardiac Disease: Home Implementation and Evaluation" (2010). College of Nursing Faculty Research and Publications. 79.

https://epublications.marquette.edu/nursing_fac/79 


\section{Authors}

Patricia Flatley Brennan, Gail Casper, Laura Burke, Kathy Johnson, Roger L. Brown, Rupa Valdez, Margaret Sebern, Oscar Perez, and Billie Sturgeon 


\title{
Technology-Enhanced Practice for Patients with Chronic Cardiac Disease: Home Implementation and Evaluation
}

\author{
Authors: Patricia Flatley Brennan, RN, PhD, FAAN, ${ }^{a}$ Gail R. Casper, RN, PhD, ${ }^{a}$ Laura J. \\ Burke, RN, PhD, FAAN, ${ }^{b}$ Kathy A. Johnson, RN, MS, ${ }^{a}$ Roger Brown, PhD, ${ }^{a}$ Rupa S. \\ Valdez, MS, ${ }^{\text {a }}$ Marge Sebern, RN, PhD, ${ }^{c}$ Oscar A. Perez, MS, ${ }^{a}$ and Billie Sturgeon, RN, \\ $\mathrm{BSN}^{\mathrm{a}}$
}

Abstract: Objective: This 3-year field experiment engaged 60 nurses and 282 patients in the design and evaluation of an innovative home-care nursing model, referred to as technology-enhanced practice (TEP).

Methods: Nurses using TEP augmented the usual care with a web-based resource (HeartCarell) that provided patients with self-management information, self-monitoring tools, and messaging services.

Results: Patients exposed to TEP demonstrated better quality of life and self-management of chronic heart disease during the first 4 weeks, and were no more likely than patients in usual care to make unplanned visits to a clinician or hospital. Both groups demonstrated the same long-term symptom management and achievements in health status.

Conclusion: This project provides new evidence that the purposeful creation of patient-tailored web resources within a hospital portal is possible; that nurses have difficulty with modifying their practice routines, even with a highly-tailored web resource; and that the benefits of this intervention are more discernable in the early postdischarge stages of care.

Chronic cardiac diseases, including congestive heart failure and coronary artery disease, represent a set of complex health problems that feature a wide range of debilitating symptoms and a constant threat of morbidity. The care of this patient population has changed dramatically over the past 20 years, with changes characterized by shorter lengths of stay, ${ }^{1}$ a greater attention to home care, ${ }^{2,3}$ and the expanded use of technology. ${ }^{4,5}$ An effective management of chronic disease requires intensive inpatient and community-based interventions, a high level of participation by patients and clinicians, and the ability to respond rapidly to an ever-changing portfolio of symptoms. Home-based interventions, both human and technological (particularly those that afford an early recognition and management of clinical problems), were shown to be 1 Flatey Brennan, Casper, Burke, Johnson, Brown, Valdez, Sebern, Perez \& Sturgeon 
effective in reducing readmission rates. ${ }^{5}$ However, most successful interventions involve evidence studies of people with mild disease, ${ }^{6}$ and rarely demonstrate effects in areas that portend long-term gains, such as self-management. These changes are likely to occur only when technological interventions are systematically designed to support, complement, and extend professional nursing interventions. Creating such interventions requires user-centered design strategies, assessment and modifications of workflow, and high levels of engagement by patients. Here we report on a 3-year field experiment assessing the impact of a technology-enhanced practice (TEP) model of care on outcomes for patients with chronic cardiac disease. TEP represents an amalgam of professional nursing practice and computer systems purposefully built to support selected components of patient care. Professional nurses, in consultation with their patients, select which functions of technology complement the aspects of care they are trying to deliver. We focused on home care nursing, and provided professional nurses and their patients with a web resource that included education, self-monitoring tools, and a communication function.

We previously reported on the processes of designing and developing the TEP;,8 TEP training for the home care agency; ${ }^{9}$ facilitators and barriers to the implementation of TEP by nurses; ${ }^{10}$ and patterns of use of the technology by participants. ${ }^{11}$ Here we report on a field study evaluating the impact of TEP on selected outcomes of home care patients with chronic heart disease. We sought to answer the question, "Does TEP lead to the improvement or stabilization of patient outcomes, including self-management of chronic heart disease, clinical status, quality of life, unplanned use of services, and satisfaction with nursing care?"

\section{Background}

The home care nursing management of patients with chronic cardiac disease has focused on three core elements: (1) education of patient and family (eg, risk factors, medications and compliance, diet), (2) symptom monitoring (first by the nurse and then by the patient), and (3) close communication with healthcare providers. Advances in technology and an increased use of the Internet by lay people make possible the current technology-based interventional research aimed at increasing patient self-management skills, improving quality of life, and avoiding emergent hospitalizations.

Research in this area has taken advantage of technology to support cardiac patients by addressing one or a combination of elements. Transtelephonic monitoring, ${ }^{12} 2$-way telemedicine

audiovisual systems, ${ }^{13,14}$ and special-purpose monitoring devices such as the HealthBuddy ${ }^{15}$

2 Flatey Brennan, Casper, Burke, Johnson, Brown, Valdez, Sebern, Perez \& Sturgeon 
address symptom monitoring. Clinically meaningful and statistically significant improvements in blood-pressure levels resulted from a 1-year exposure to usual care that was enhanced by telephonic monitoring. However, the technological intervention stood separate from the clinical practice. ${ }^{16,17}$ Home monitoring also led to improved energy expenditures among older adults with high disease burden after cardiac surgery. The Med-eMonitor, which prompts patients with congestive heart failure about diet, activity, compliance with medications, and answers to patients' questions about symptoms, blood pressure, and weight, ${ }^{18}$ addresses both monitoring and education.

The first HeartCare Study pulled together these three threads. We provided Internet-based information and support for patients experiencing a full recovery trajectory after coronary artery bypass graft surgery. ${ }^{19}$ Similarly, Westlake et $\mathrm{al}^{20}$ demonstrated the effects of a web-based education, including the capability to e-mail a clinical nurse specialist and other study participants, with links to web video content. This study, HeartCare II, builds on the successes of HeartCare I and other pioneering efforts in this field, in this case weaving the threads of education, symptom monitoring, and communication to intuitive, interactive web-based tools to help nurses teach patients to learn how to manage their health. The result was a new model of nursing care, TEP.

Using technology to engage patients and nurse professionals in managing chronic cardiac disease is challenging. For patients, developing an understanding of what self-management actually means through the trajectory of the disease process, and not simply when the nurse is present, is required. ${ }^{21}$ For nurses, the introduction and integration of technology requires a different way of thinking about the delivery of nursing care. Many home care nurses believe that the "relational aspects of the nurse-patient relationship ... hold the greatest significance for both nurses and elderly people... The therapeutic value of visits reaffirms their core values." 22 Introducing information technology into this interpersonally rich dyadic relationship proved challenging.

We report on the effects of this novel practice model, TEP, on patient self-management, quality of life, health status, satisfaction with nursing care, and unplanned service use. The intention of this project was not to prescribe how the technology should be used, but rather to give the home care nurse a toolbox to be implemented in terms of a specific patient and context, without disrupting the established workflow or relational aspects of care. As a result, there was no uniform exposure or dose of TEP; instead a wide range of use, dependent on the context and on mental models of both the patient and nurse occurred.

3 Flatey Brennan, Casper, Burke, Johnson, Brown, Valdez, Sebern, Perez \& Sturgeon 


\section{Materials and Methods}

\section{Setting and sample}

This field experiment took place in the homes of patients recruited from a single home care agency of a large, integrated healthcare delivery system. This home care agency is geographically distributed across rural, suburban, and urban areas in a Midwestern state. The agency is divided into offices, each staffed by professional nurses and home health aides, and serves about 25,000 patients annually. Patients referred for home care services are assigned to offices according to the location of their primary residence.

At the beginning of the study, 6 agency offices were matched into 3 pairs representing rural, suburban, and urban areas. Offices within each pair were randomly assigned to one of the two study conditions. Ten months into this 30-month study, the 2 urban offices merged for administrative reasons. The combined office was then assigned to the experimental condition. Merging the 2 offices did not affect the demographic mix of participants.

All patients admitted to the home care agency for the receipt of nursing care, and deemed eligible for the study, were assigned to the study condition to which that office had been assigned. Eligibility criteria included an International Classification of Diseases-9 (ICD-9) coded medical diagnosis indicating the presence of primary or secondary chronic cardiac disease, clinical stability, the ability to read and write English, a working analogue telephone line, and residence within a 100-mile radius of the central office for the home care agency. Exclusion criteria comprised attributes that impaired an individual's active use of information technology, including mental or sensory incapacity, or a requirement for in-home, continuous, professional care. We screened 4033 patients, contacted 2303, and recruited 282 into the study. The consent rate was comparable across all clinical sites. Fig 1, a modified Consolidated Standards of Reporting Trials (CONSORT) flow diagram, illustrates the recruitment, accrual, and loss of participants throughout the study.

\section{Variables}

Independent variable

The independent variable was the nursing practice model. Two types of nursing practice models were compared in this study: usual care and TEP. The models were similar in terms of scope, duration of contact, and expected outcomes. The models differed in the extent to which web technology supported the nurse and patient in the nursing care process. Usual care

4 Flatey Brennan, Casper, Burke, Johnson, Brown, Valdez, Sebern, Perez \& Sturgeon 
Care was based on the nurse's assessment of a patient's needs, the physician's orders, and clinical guidelines. The patient's medical diagnosis, the patient's acuity, the physician's orders, the insurance coverage, and the nursing care needs determined the number of home visits to be made, typically ranging from 1 to 9 . Nurses interacted with patients through home visits and telephone calls for the specified number of visits, typically spanning several weeks. Patient and family education were integral components of care. Nurses used an institutional set of care management initiative educational materials to assist patients with adhering to medications, modifying lifestyle, understanding their disease, and recognizing early manifestations of disease progression or complications. In addition to education, the practices include the surveillance of cardiopulmonary symptoms, prompt response to a change in status, and the coordination of services. All tools were paper-based.

\section{Technology-enhanced practice}

The intervention, TEP, is a nursing practice model in which nurses selectively and deliberately use information technologies to meet individual patient care goals. Nurses plan and provide nursing care, supplementing their usual practice with selected technology tools located on the HeartCare website, to provide care tailored to patients' specific needs, abilities, and illness trajectories. These tools resulted from work in the design phase of the study, through the use of human-factors techniques to solicit input from and analyze the work of home care nurses. The specific technology tools developed either replaced paper forms or filled an identified gap in assessment or educational needs. The suite of technology tools, housed on the HeartCare website within the clinical partner's clinical information system, could be accessed by both nurses and patients through an Internet connection. The interactive technology tools (Table 1) on the HeartCare website addressed education (patient education resources on a variety of topics. eg, disease, medication, and drug interaction information, plus food trackers), symptom monitoring (eg, a symptom checklist, weight tracker, blood pressure tracker, and heart rate tracker), and communication (eg, my goals, my journal, email, and bulletin boards).

\section{Outcome measures and instruments}

\section{Clinical status}

The Short Form-12 (SF-12) is a 12-item measure used as an indicator of a patient's physical and mental functional clinical status. ${ }^{23} \mathrm{~A}$ weighted additive model is used to calculate both a physical and mental health status, each scored on a scale from 0 to 100 . A higher score is indicative of a better health status. A shortened version of the SF-36, the SF-12 is based on the assumption that only 1 or 2 questionnaire items are necessary to estimate the average score in

5 Flatey Brennan, Casper, Burke, Johnson, Brown, Valdez, Sebern, Perez \& Sturgeon 
terms of a concept for a population, or to determine the overall prevalence of scores in either the best or most impaired categories of the 8 most frequently measured health domains. ${ }^{24}$

\section{Self-management}

The Self-Care Heart Failure Index (SCHFI) is a 17-item measure of self-care in patients

with heart failure. ${ }^{25}$ Self-management was measured with a subscale from the Self-Care in Heart Failure Index (SCHFI). The SCHFI measures behaviors that maintain physiological stability, the response to symptoms when they occur, and self-confidence. The 5-item self-maintenance subscale of this instrument, addressing physiological stability, is in close concordance with our viewpoint on the self-management skills required of this patient population (a coefficient of .55; 95\% confidence interval, .43 to .65). Participants are asked to respond on a 4-point Likert-type scale (ie, never or rarely, sometimes, frequently, or always) to how often they perform several activities that are important in chronic cardiac conditions: weighing themselves daily, taking part in physical activity, eating a low-salt diet, checking their ankles for swelling, and keeping their weight down. Summary scores are standardized on a scale from 0 to 100, with a higher score indicative of better self-management. Riegel et $\mathrm{al}^{26}$ suggested that an 8-point increase in the SCHFI subscales is clinically meaningful.

\section{Quality of life}

Quality of life was measured using the Multidimensional Index for Life Quality Questionnaire for Cardiovascular Disease (MILQ), a 35-item scale that covers 9 domains identified as critical for patients with coronary disease. ${ }^{27}$ Items are scored on a 7-point Likert scale. The score is calculated by doubling the mental health satisfaction subscore and adding it to the physical health satisfaction subscore. The range of this composite score is 12 to 84 , with a higher score indicative of greater satisfaction with quality of life. ${ }^{27}$

\section{Satisfaction with nursing care}

This organization-specific survey is routinely administered by the home care nursing agency for purposes of quality assurance. Patients are asked to rate their satisfaction on 15 items related to nursing care on a phrase-anchored scale (range, 1 to 5), eg, the nurse is knowledgeable about care, the nurse explains medications, or the nurse provides information to manage care between visits. These scores are combined using an additive model, and the summary score is standardized on a scale of 0 to 100 , with a higher score indicative of greater satisfaction with nursing care.

\section{Unplanned service use}

Unplanned service use included unexpected clinic or physician's office appointments, 
emergency department visits, and unplanned hospitalizations. The use of any of these services was recorded dichotomously (yes or no) at each data collection point. Data were obtained through self-report, and verified for a subset of respondents through chart review.

\section{Explanatory variables}

\section{Demographics and descriptors}

The study coordinator collected standard demographic and descriptive information about participants at baseline, including gender, age, race, ethnicity, educational level, experience with computers, and number of chronic illnesses (according to patient self-report). The Specific Activities Scale (SAS), a 5-item measure of functional status under nonacute conditions, ${ }^{28}$ was used to indicate disease severity. This scale categorizes the severity of a patient's symptoms of heart failure from Class I (without limitation of physical activity) to Class IV (inability to perform any physical activity without discomfort). The SAS scores were described to be more valid and reliable than scores estimated using the familiar New York Heart Association classification. ${ }^{28}$

\section{Procedure}

Approval for the use of human subjects was obtained for the study. A research nurse screened patients admitted to the home care agency on a daily basis. The study coordinator screened potential participants for eligibility, using the agency's electronic admission records. Potential patients were telephoned to verify their eligibility, briefly explain the study, and gain consent to meet with them at their homes. During the home visit, the study was fully explained, consent was obtained, and baseline data were collected. Participants remained in the study for 24 weeks.

\section{Technology-enhanced practice intervention}

Training methods for nurses emphasized active participation and learning. Training involved screen-capture videos of website tools, training outlines, tips on teaching the elderly, practice-teaching scenarios, a pocket guide to website tools, a guide mapping website tools to the agency's home visit guidelines, and a CD with narrated webcam demonstrations of website tools. To assist nursing staff in tailoring TEP to their own practice style and patient needs, several support strategies were used. This support included providing home care nurses with "first-visit support" by a research team member in the patient's home to reinforce TEP training, one-on-one and small-group retraining approximately 12 months into the experiment, monthly staff meetings attended by research liaison nurses to provide project updates and answer questions, and ongoing troubleshooting by the research nurse and agency help desk with home care nurses to manage daily implementation issues. Bimonthly newsletters for the experimental

7 Flatey Brennan, Casper, Burke, Johnson, Brown, Valdez, Sebern, Perez \& Sturgeon 
and comparison offices provided project highlights, reminders, and motivational messages.

Unlike other studies of home care interventions where nurses follow a set protocol with every patient, our TEP allowed, and even required, nurses to create the right mix of in-person nursing care and technology-delivered interventions. During home visits, nurses chose technology tools that addressed patient needs and goals, used these tools interactively with patients, taught patients to use these tools independently between visits, and selectively monitored their use between visits.

Patients in the TEP intervention group received either a web computer or modifications to their own computers that enabled them to access Heart-Care II resources. Patients received a written manual and pocket guide describing website access and use. Both nurses and patients could access the suite of technology tools, housed on the HeartCare section within the agency's public portal, through a standard web browser and Internet connection.

Patients were encouraged to use technology tools on their own between their nurse's visits and after the termination of home care nursing services, for education and self-monitoring. Based on the available tracing data of logins, participants accessed the HeartCare website from 0 to 314 times over the course of 24 weeks (mean, 19 weeks; SD, 40.6 weeks). Approximately $50 \%$ of participants continued to log in to the HeartCare II website for 4 weeks. This declined to $33 \%$ at 8 weeks, whereas $15 \%$ continued to log in for the 24 -week duration of the study. ${ }^{11}$

\section{Data collection and management}

Exposure to the experimental conditions (TEP vs. usual care) was treated as a dichotomous variable (using usual care as a reference). Data for explanatory (baseline only) and dependent variables were collected at 6 points: baseline (in-home interview) and weeks 1, 4, 8, 12 , and 24 . A trained research nurse collected baseline data by means of a survey during in-home interviews. Survey data at subsequent time points were collectedby1 of 2 methods, based on the participant's preference: either via telephone interview by a trained research assistant, or by a mailed survey.

\section{Data cleaning and reduction}

All data were cleaned, triple-entered, and evaluated for integrity and "missingness." Little's Missingness Completely at Random (MCAR) Test, with Bonferroni correction for multiple comparisons, ${ }^{29}$ was used to check missingness. The MCAR Test demonstrated that only 2 out of a possible 30 opportunities ( 5 scales over 6 data collection points) did not meet the assumption of MCAR. The two opportunities that failed at MCAR were supported for the assumption of Missing At Random (MAR). Thus we are confident that the missingness lacked

8 Flatey Brennan, Casper, Burke, Johnson, Brown, Valdez, Sebern, Perez \& Sturgeon 
any systematic pattern. We undertook an analysis strategy for treatment effects over time, using a random-effects regression model for continuous measures, and including generalized estimating equations (GEEs) for binary unplanned service utilization. ${ }^{30}$

In addition, data from some patients were lacking for specific measurement time periods, with the result that some subjects provided data at some but not all data collection points. Laird ${ }^{31}$ indicated that the random-effects model for longitudinal data provides valid inferences in the presence of ignorable nonresponse or, in our case, random dropouts. To assess the issue of ignorability of our dropout data, we used pattern-mixture modeling, ${ }^{29,32}$ and determined that no additional adjustments were necessary.

\section{Results}

In total, 282 patients were enrolled over the 27-month recruitment period (Fig1). The sample comprised 84\%Caucasian and 8\% African American. The remaining 8\% identified themselves as Asian, Native American, Pacific Islander, and multiple races. Most participants were non-Hispanic (95\%) and male (61\%), and ranged in age from 28 to 93 years, with a mean age of 64 years (SD, 12.7 years). Most were married (60\%),and 80\% reported living with someone. Over half of the study participants had at least a high school education, with $42 \%$ reporting 13 to 16 years of education, and 19\% reporting 17 or more years. Participants were randomized by the home care office into usual care or TEP, and remained in the study for a 24-week period. The randomization process resulted in comparable participant groups in terms of major demographic and clinical-status variables (Table 2).

We used a random-effects modeling strategy to evaluate the impact of the TEP intervention on outcomes of self-management of heart failure, mental and physical health status, quality of life, unanticipated service use, and satisfaction with nursing care. We created models that accounted for scores on outcome measures at baseline and for the key covariates of gender, age, and education. The parameters listed in Table 3 demonstrate that no main effects of TEP on the major outcome variables were evident.

Fig 2 provides a graphic depiction of the major variables at the 5 postintervention data collection points, ie, weeks 1, 4, 8, 12, and 24 (note that the time intervals are not even). Fig 2 displays the patterns over time of the adjusted means. The untransformed means, compared at each point in time, are shown in Table 4. The TEP group is represented by triangles, and the usual care by circles. Interestingly, similar to our earlier work with patients after acute cardiac events, the 2 groups reach similar endpoints, but appear to possess noticeable differences in the 9 Flatey Brennan, Casper, Burke, Johnson, Brown, Valdez, Sebern, Perez \& Sturgeon 
early postdischarge stage (time periods 2 and 3). Despite appearances in the graph, none of the differences between TEP and usual care are significant at any time point for the outcome variable of satisfaction with nursing care. Although the magnitude of the difference seems large, the maximum difference comprises only 4 points, which is not clinically meaningful or statistically significant. The range of scores for both groups in the entire study is less than 3 points (on a 100-point scale), indicating that satisfaction with nursing care was very stable over time for both groups. Moreover, although the difference in unplanned service use appears large, it is also not significant. We present the raw (untransformed) means and standard deviations of key variables across time in Table 4, to better illustrate patterns of response.

As a follow-up analysis, we examined the fixed-effects interaction of treatment by time, using post hoc multiple-comparison tests (reporting both raw probabilities and Sidak adjustments). Comparing treatment levels at each time point may aid in understanding the nature of an effect. Adjustments in $\mathrm{P}$ values need to be made when multiple tests are performed. ${ }^{33}$ These adjustments are usually performed to preserve the family-wise error rate (FWER) of a group of tests. The FWER is the probability of incorrectly rejecting at least one pairwise test. Table 5 illustrates the mean TEP/usual care difference assessed, using paired contrasts adjusted for covariates.

These analyses revealed a significant difference between TEP and usual care in terms of both physical health (at weeks 1 and 4) and mental health (at weeks 1 and 8 ). These results are in accordance with the Sidak adjustment. The fixed time-point exploration revealed no effect of TEP on quality of life or self-management at any time point, and no systematic effect.

\section{Discussion}

The TEP is a model of nursing care that augments the practice strategies available to the home care nurse by providing web-based educational, symptom-monitoring, and communication tools that can be tailored to an individual patient's needs and care plan. This model of care afforded improved outcomes and better self-management of chronic cardiac conditions for persons receiving home care nursing. These outcomes were most discernable in the early posthospital period, with the strongest influences on physical and mental function constructs. Our results were in keeping with the impact of other technological interventions, in that they (1) affected psychological and physical function rather than behaviors or knowledge, ${ }^{31-37}$ and (2) improved outcomes particularly in the early postdischarge period. Unlike the study of Artinian et al, ${ }^{16}$ where participants had ongoing exposure to the intervention over an entire year, our

10 Flatey Brennan, Casper, Burke, Johnson, Brown, Valdez, Sebern, Perez \& Sturgeon 
participants had exposure to the full TEP intervention only during the first half of the observational period. We hypothesized that it was unreasonable to expect distal effects to persist or arise simply because of the ability to access the HeartCare web server. The engagement of the home care nurse is critical to the TEP model of care.

The modest impact of TEP may be explained by the poor health status of our participants. Our participants were sicker than those in most other interventional studes, ${ }^{5,6,12,14}$ with $79.5 \%$ scoring at a level of 3 or 4 on the SAS. For these patients, TEP may have provided a greater sense of security and support, rather than overall improvement in self-management. This finding in itself represents a significant challenge to contemporary thinking about home care nursing and to studies of consumer health technology, ${ }^{38}$ where the intervention is designed to shift the responsibility for care more to the patient and off of the care-providing system.

An interesting and relatively unexplored area involves the interaction between technology resources and the cognitive burden of cardiac disease. Jurgens et al demonstrated that cardiac patients have difficulty understanding and interpreting their symptoms. ${ }^{39}$ Because strong positive effects of the intervention on the SF-12 mental variable occurred concurrent with the home care intervention exposure, the TEP may support the cognitive needs of a patient by providing just-in-time coaching, whereas the home care nurse addresses remedial physical demands.

The intention of this project was not to prescribe how the technology should be used, but to give the home care nurse a toolbox that could be implemented specific to a patient's needs and context, without disrupting the established workflow. Thus, the degree of integration of this technology into the workflow was at the discretion of the nurse, and was influenced by the nurse's perceptions of a patient's acuity, the time available to incorporate the technology, and the nurse's own comfort with the technology. Evidence from focus-group explorations of our nursing staff suggests that the nurses' discretionary use of the technological intervention in TEP was grounded in a large number of factors, including the nurses' comfort with the technology, their appraisal of a patient's level of skill and interest, and general practice logistics. ${ }^{10}$ Because the trial was conducted in a real clinical setting, the intervention was affected by organizational changes and modifications in basic technology. For example, the appearance and navigation of web resources were affected when the home care agency updated its clinical information system. Although the presence and functionality of tools and educational resources remained constant, the layout and navigation of web pages varied during the course of the study, and may have influenced nurses' engagement in integrating the technology tools into their care practices with patients.

11 Flatey Brennan, Casper, Burke, Johnson, Brown, Valdez, Sebern, Perez \& Sturgeon 
The intervention did not reduce unplanned service use. Our participants were similar to those of Woodend et al, ${ }^{5}$ who found that $56 \%$ of their 121 patients with a primary diagnosis of heart failure had at least one visit to the emergency department during the first year. Unlike findings from other studies of consumer technologies, ${ }^{15,40}$ participants in the TEP group showed a slight increase in health service use. However, Sacks et $\mathrm{al}^{40}$ addressed a generally healthy population, whereas our project is one of the few to address a seriously ill population. The increase in service use may have resulted from patients' greater recognition and willingness to act on symptoms.

\section{Conclusions}

The TEP offers a promising intervention to support the posthospital care of persons with chronic cardiac disease. Although not supplanting existing nursing services, the TEP may better attend to the clinical and psychological needs of patients, augmenting education, symptom monitoring, and communication opportunities. The TEP will not likely accelerate self-management, and determining the appropriateness of self-management as a goal for care should be reexamined.

\section{Notes}

- The authors gratefully acknowledge the support of grant LM6249, Custom Computerized Home Care for Cardiac Disease, from the National Institutes of Health to P.F.B.

- From the aniversity of Wisconsin Madison School of Nursing, Madison, Wisconsin; ${ }^{\mathrm{b}}$ Aurora Healthcare, Milwaukee, Wisconsin; and ${ }^{\mathrm{C} M a r q u e t t e}$ University College of Nursing, Milwaukee, Wisconsin.

- Corresponding author: Patricia Flatley Brennan, RN, PhD, FAAN, University of Wisconsin Madison School of Nursing, Madison, WI 53792. E-mail: pbrennan@engr.wisc.edu

\section{References}

1. Splaine Wiggins M. The partnership care delivery model: an examination of the core concept and the need for a new model of care. J Nurs Manag 2008;16:629-38.

2. Naylor MD. A decade of transitional care research with vulnerable elders. J Cardiovasc Nurs 2000;14:1-14.

3. Ni H, Nauman DJ, Hershberger RE. Analysis of trends in hospitalizations for heart failure. J Card Fail 1999;5:79-84.

12 Flatey Brennan, Casper, Burke, Johnson, Brown, Valdez, Sebern, Perez \& Sturgeon 
4. Edwardson SR. Patient education in heart failure. Heart Lung 2007;36:244-5.

5. Woodend AK, Sherrard H, Fraser M, Stuewe L, Cheung T, Struthers C. Telehome monitoring in patients with cardiac disease who are at high risk of readmission. Heart Lung 2008;37: 36-45.

6. DeBusk RF, Miller NH, Parker KM, et al. Care management for low-risk patients with heart failure: a randomized, controlled trial. Ann Intern Med 2004;141:606-13.

7. Or CKL, Casper GR, Karsh B, et al. Work system analysis of home nursing care and implications for patient safety. Proc Hum Factors Ergonomics Soc 2005;1052-6.

8. Casper GR, Karsh B, Or CKL, Carayon P, Grenier AS, Brennan PF. Designing a technology enhanced practice for home nursing care of patients with congestive heart failure. AMIA Annu Symp Proc 2005;116-20.

9. Kossman SP, Casper GR, Severtson DJ, et al. Designing study nurses' training to enhance research integrity: a macroergonomic approach. AMIA Annu Symp Proc 2006;439-43.

10. Johnson KA, Valdez RS, Casper GR, et al. Experiences of technology integration in home care nursing. AMIA Annu Symp Proc 2008;389-93.

11. Casper GR, Brennan PF, Burke LJ, Nicolalde D. HeartCarell: patients' use of a home care web resource. Stud HealthTechnol Inform 2009;146:139-43.

12. Benatar D, Bondmass M, Ghitelman J, Avitall B. Outcomes of chronic heart failure. Arch Intern Med 2003;163:347-52.

13. Jenkins $R L$, McSweeney M. Assessing elderly patients with congestive heart failure via in-home interactive telecommunication. J Gerontol Nurs 2001;27:21-7.

14. Jerant AF, Azari R, Nesbitt TS. Reducing the cost of frequent hospital admissions for congestive heart failure: a randomized trial of a home telecare intervention. MedCare 2001;39:1234-45.

15. Barnason S, Zimmerman L, Nieveen J, Hertzog M. Impact of a telehealth intervention to augment home health care on functional and recovery outcomes of elderly patients undergoing coronary artery bypass grafting. Heart Lung 2006;35: 225-33.

16. Artinian NT, Flack JM, Nordstrom CK, et al. Effects of nurse-managed telemonitoring on blood pressure at 12-month follow-up among urban African Americans. Nurs Res 2007; 56:312-22.

17. Barnason S, Zimmerman L, Schulz P, Tu C. Influence of an early recovery telehealth intervention on physical activity and functioning after coronary artery bypass surgery among older adults with high disease burden. Heart Lung 2009;38:459-68.

13 Flatey Brennan, Casper, Burke, Johnson, Brown, Valdez, Sebern, Perez \& Sturgeon 
18. Artinian NT, Harden JK, Kronenberg MW, et al. Pilot study of a web-based compliance monitoring device for patients with congestive heart failure. Heart Lung 2003;32:226-33.

19. Brennan PF, Moore SM, Bjornsdottir G, Jones J, Visovsky C, Rogers M. HeartCare: an internet-based information and support system for patient home recovery after coronary artery bypass graft (CABG) surgery. J Adv Nurs 2001;35:699-708.

20. Westlake C, Evangelista LS, Strömberg A, Ter-Galstanyan A, Vazirani S, Dracup K. Evaluation of a web-based education and counseling pilot program for older heart failure patients. Prog Cardiovasc Nurs 2007;22:20-6.

21. Horowitz CR, Rein SB, Leventhal H. A story of maladies, misconceptions and mishaps: effective management of heart failure. Soc Sci Med 2004;58:631-43.

22. McGarry J. Defining roles, relationships, boundaries and participation between elderly people and nurses within the home: an ethnographic study. Health Soc Care Community 2009;17:83-91.

23. Resnick B, Nahm ES. Reliability and validity testing of the revised 12-item short-form health survey in older adults. J Nurs Meas 2001;9:151-61.

24. Ware J Jr, Kosinski M, Keller SD. A 12-item short-form health survey: construction of scales and preliminary tests of reliability and validity. Med Care 1996;34:220-33.

25. RiegelB, CarlsonB, Moser DK, SebernM, Hicks FD, RolandV. Psychometric testing of the self-care of heart failure index. J Card Fail 2004;10:350-60.

26. Riegel B, Lee CS, Dickson VV, Carlson B. An update on the self-care of heart failure index. J Cardiovasc Nurs 2009;24:485-97.

27. Avis ND, Smith KW, Hambleton RK, Feldman HA, Selwyn A, Jacobs A. Development of the multidimensional index of life quality. A quality of life measure for cardiovascular disease. Med Care 1996;34:1102-20.

28. Goldman L, Hashimoto B, Cook EF, Loscalzo A. Comparative reproducibility and validity of systems for assessing cardiovascular functional class: advantages of a new specific activity scale. Circulation 1981;64:1227-34.

29. Little RJA. Modeling the drop-out mechanism in repeated-measures studies. J Am Stat Assoc 1995;90:1112-21.

30. Liang KY, Zeger SL. Longitudinal data analysis using generalized estimating equations. Biometrika 1986;73:13-22.

31. Laird NM. Missing data in longitudinal studies. Stat Med 1988;7:305-15.

32. Hedeker D, Gibbons RD. Application of random-effects pattern-mixture models for missing

14 Flatey Brennan, Casper, Burke, Johnson, Brown, Valdez, Sebern, Perez \& Sturgeon 
data in longitudinal studies. Psychol Methods 1997;2:64-78.

33. Hochberg Y, Tamhane AC. Multiple comparison procedures. New York: John Wiley \& Sons; 1987.

34. Brennan PF, Moore SM, Smyth KA. The effects of a special computer network on caregivers of persons with Alzheimer's disease. Nurs Res 1995;44:166-72.

35. Brennan PF. Computer network home care demonstration: a randomized trial in persons living with AIDS. Comput Biol Med 1998;28:489-508.

36. Moore SM, Charvat JM, Gordon NH, et al. Effects of a CHANGE intervention to increase exercise maintenance following cardiac events. Ann Behav Med 2006;31:53-62.

37. Zimmerman L, Barnason S. Use of a telehealth device to deliver a symptom management intervention to cardiac surgical patients. J Cardiovasc Nurs 2007;22:32-7.

38. Demiris $G$. The diffusion of virtual communities in health care: concepts and challenges. Patient Educ Couns 2006;62:178-88.

39. Jurgens C, Holke L, Byrnes J, Riegel B. Why do elders delay in responding to heart failure? Nurs Res 2009;58:274-82.

40. Sacks N, Cabral H, Kazis LE, et al. A web-based nutrition program reduces health care costs in employees with cardiac risk factors: before and after cost analysis. J Med Internet Res 2009; $11: e 43$.

\section{Appendix}

\section{Analysis Appendix}

Analysis

Our analysis strategy for treatment effects used a random-effects regression model for longitudinal data. The model in terms of $n_{i} \times 1$ vector of responses across time, $y_{i}$, for subject $i$ may be defined as:

$$
\underset{n_{i} \times 1}{y_{i}}=\underset{n_{i} \times p}{X_{i}} \underset{p \times 1}{\beta}+\underset{n_{i} \times r}{Z_{i}} \underset{r \times 1}{v_{i}}+\underset{n_{i} \times 1}{\varepsilon_{i}}
$$

where $y_{i}=$ the $n_{i} \times 1$ vector of outcome measures for subject $i, X_{i}=a$ known $n_{i} \times p$ design matrix, $\beta=a p \times 1$ vector of unknown population parameters, $Z_{i}=a$ known $n_{i} \times r$ design matrix, $v_{i}=$ the $r \times 1$ vector of unknown subject effects distributed $N(0, \Sigma v)$, and $\varepsilon_{i}=$ the $\mathrm{n}_{\mathrm{i}} \times 1$ vector of random residuals, distributed independently as $\mathrm{N}\left(0, \Sigma_{\varepsilon \mathrm{i}}\right)$.

Our subjects were measured across 5 time periods of $1,4,8,12$, and 24 weeks. Because not all our outcome measures were continuous measures, we adapted the model to handle our binary outcome measure of service utilization, using GEEs for longitudinal data. ${ }^{1}$

In our study, some patients were missed at specific measurement time periods, with the result that some subjects provided data at some but not all study time periods. Laird indicated that the random-effects model for longitudinal data provides valid inferences in the presence of ignorable nonresponse, or in our case random dropouts. ${ }^{2}$ To assess the issue of ignorability of 15 Flatey Brennan, Casper, Burke, Johnson, Brown, Valdez, Sebern, Perez \& Sturgeon 
our dropout data, we used pattern-mixture modeling. ${ }^{3,4}$ In our analysis, the pattern was defined as completers vs. noncompleters (partial respondents). The treatment effect across time varied according to completion status, and the effects were adjusted as suggested by Hogan and Laird. ${ }^{5}$ The adjustment is based on the averaged estimates for the effect parameter (b), which is equal to:

$$
\hat{\bar{\beta}}=\hat{\pi}_{c} \hat{\beta}_{c}+\left(1-\hat{\pi}_{c}\right) \hat{\beta}_{d}
$$

where $\pi_{c}$ represents the population weights for completers, with $\left(1-\pi_{c}\right)$ for dropouts. To obtain adjusted standard errors, the delta method, as described by Hogan and Laird ${ }^{5}$ was used.

A follow-up analysis examined the fixed-effects interaction of treatment by time, using post hoc multiple comparison tests, because comparing treatment levels at each time point may aid in understanding the nature of an effect. Adjustments in $\mathrm{P}$ values need to be made when multiple tests are performed. ${ }^{6}$ Adjustments were performed to preserve the FWER of the group of tests. The FWER involves the probability of incorrectly rejecting at least one pairwise test.

\section{Appendix References}

1. Liang K-Y, Zeger SL. Longitudinal data analysis using generalized estimating equations. Biometrika 1986;73:13-22.

2. Laird NM. Missing data in longitudinal studies. Stat Med 1988; 7:305-15.

3. Little RJA. Modeling the drop-out mechanism in repeated-measures studies. J Am Stat Assoc 1995;90:1112-21.

4. Hedeker D, Gibbons RD. Application of random-effects pattern-mixture models for missing data in longitudinal studies. Psychol Methods1997;2:64-78.

5. Hogan JW, Laird NM. Mixture models for the joint distribution of repeated measures and event times. Stat Med 1997;16: 239-58.

6. Hochberg Y, Tamhane AC. Multiple comparison procedures. New York: John Wiley\& Sons; 1987.

\section{Table 1}

\section{Comparison of usual care and TEP}

\begin{tabular}{|c|c|c|}
\hline Usual Care & Task & TEP \\
\hline $\begin{array}{l}\text { Nurse selection of } \\
\text { commonly used } \\
\text { paper-based materials }\end{array}$ & Education & $\begin{array}{l}\text { All web-based resources (e.g., disease, medication. and } \\
\text { drug interaction information) available to all patients, } \\
\text { and incorporated into care plan through nurse-patient } \\
\text { discussion. Food Tracker, For Your Well-being }\end{array}$ \\
\hline $\begin{array}{l}\text { Patient-recorded } \\
\text { symptom grid }\end{array}$ & $\begin{array}{l}\text { Symptom } \\
\text { monitoring }\end{array}$ & $\begin{array}{l}\text { Symptom Checklist Weight Tracker, Blood Pressure } \\
\text { Tracker, Heart Rate Tracker, Fluid Tracker, Blood } \\
\text { Sugar Monitor }\end{array}$ \\
\hline Telephone & Communication & My Goals, My Journal, e-mail, bulletin boards \\
\hline
\end{tabular}

16 Flatey Brennan, Casper, Burke, Johnson, Brown, Valdez, Sebern, Perez \& Sturgeon 


\section{Table 2}

Baseline profile of enrolled participants according to treatment group

\begin{tabular}{|c|c|c|c|c|c|c|c|c|}
\hline & $\begin{array}{c}\text { Technology-enhanced } \\
\text { practice }\end{array}$ & & & & Usual care & & & \\
\hline & $\mathbf{N}$ & $\mathbf{n}$ & $\%$ & Mean (SD) & $\mathbf{N}$ & $\mathbf{n}$ & $\%$ & Mean (SD) \\
\hline Age & 146 & & & $64.26(12.54)$ & 136 & & & $63.74(12.91)$ \\
\hline $\begin{array}{l}\text { Years of } \\
\text { education }\end{array}$ & 146 & & & $14.09(3.97)$ & 135 & & & $14.1(3.53)$ \\
\hline Male gender & 146 & 86 & 58.9 & & 135 & 85 & 62.5 & \\
\hline $\begin{array}{c}\text { Specific activity } \\
\text { scale (SAS) } \\
\text { class (III+) }\end{array}$ & 146 & 116 & 79.5 & & 135 & 107 & 79.3 & \\
\hline $\begin{array}{l}\text { Number of } \\
\text { chronic } \\
\text { illnesses }\end{array}$ & 145 & & & $2.54(1.43)$ & 135 & & & $2.51(1.43)$ \\
\hline
\end{tabular}

Table 3

General linear mixed-model results of study outcomes over time

\begin{tabular}{|c|c|c|c|c|c|c|}
\hline $\begin{array}{l}\text { Outcome } \\
\text { variables }\end{array}$ & $\begin{array}{l}\text { Clinical } \\
\text { status }\end{array}$ & $\begin{array}{l}\text { Clinical } \\
\text { status }\end{array}$ & $\begin{array}{l}\text { Self- } \\
\text { maintenance }\end{array}$ & $\begin{array}{c}\text { Quality of } \\
\text { life }\end{array}$ & $\begin{array}{c}\text { Satisfaction } \\
\text { with nursing } \\
\text { care }\end{array}$ & $\begin{array}{l}\text { Unplanned } \\
\text { service use }\end{array}$ \\
\hline Instrument & $\begin{array}{l}\text { SF-12 } \\
\text { Physical }\end{array}$ & SF-12 Mental & $\begin{array}{l}\text { SCHFI Self- } \\
\text { Maintenance }\end{array}$ & MILQ & $\begin{array}{l}\text { Satisfaction } \\
\text { with } \\
\text { Nursing } \\
\text { Care }\end{array}$ & $\begin{array}{l}\text { Service } \\
\text { Utilization }\end{array}$ \\
\hline Time & $.094(.008)^{*}$ & $116.9(24.0)^{*}$ & $-299.5(57.5)^{*}$ & $250.4(35.7)^{*}$ & $-.299(.375)$ & $.048(.077)$ \\
\hline Group & $.094(.028)^{*}$ & $294.0(109.5)^{*}$ & $102.5(249.5)$ & $308.7(136.3)^{*}$ & $-.938(1.593)$ & $.297(.353)$ \\
\hline Time* Group & $-.016(.011)$ & $-49.43(33.84)$ & $48.02(80.83)$ & $-64.41(50.13)$ & $.202(.540)$ & $.011(.104)$ \\
\hline
\end{tabular}

Standard errors are provided in parentheses. Transformations were ascertained using the Box-Cox method. All used a squared transformation except for SF-12 Physical, which used a log transformation. * $P$ $<0.05$

17 Flatey Brennan, Casper, Burke, Johnson, Brown, Valdez, Sebern, Perez \& Sturgeon 
Table 4

Untransformed means and standard deviations of major outcomes across time

\begin{tabular}{|c|c|c|c|c|c|c|c|c|}
\hline & & $\mathbf{N}$ & SF-12 Physical & SF-12 Mental & $\begin{array}{c}\text { SCHFI } \\
\text { self-maintenance }\end{array}$ & MILQ & $\begin{array}{c}\text { Satisfaction with } \\
\text { nursing care }\end{array}$ & $\begin{array}{c}\text { Service } \\
\text { utillization }\end{array}$ \\
\hline \multirow{2}{*}{ Baseline } & TEP & 146 & $28.63(6.52)$ & $45.57(10.03)$ & $82.43(13.95)$ & $59.97(11.19)$ & $73.38(12.68)$ & $12.3 \%$ \\
\hline & Usual care & 135 & $29.44(5.94)$ & $43.13(10.58)$ & $82.47(15.71)$ & $56.32(13.22)$ & $72.79(14.27)$ & $12.5 \%$ \\
\hline \multirow[t]{2}{*}{1 week } & TEP & 127 & $31.16(7.86)$ & $49.40(10.37)$ & $83.17(12.43)$ & $61.19(13.11)$ & $87.14(12.93)$ & $15 \%$ \\
\hline & Usual care & 128 & $28.63(6.26)$ & $46.19(10.29)$ & $82.05(12.98)$ & $56.78(13.00)$ & $88.16(12.05)$ & $14.1 \%$ \\
\hline \multirow[t]{2}{*}{4 weeks } & TEP & 119 & $34.63(8.20)$ & $50.72(9.98)$ & $81.58(13.32)$ & $62.26(12.86)$ & $79.50(27.36)$ & $21 \%$ \\
\hline & Usual care & 117 & $32.11(7.84)$ & $48.91(10.08)$ & $80.20(13.73)$ & $58.89(12.39)$ & $84.74(19.77)$ & $14.5 \%$ \\
\hline \multirow[t]{2}{*}{8 weeks } & TEP & 116 & $38.87(10.36)$ & $53.43(9.20)$ & $78.80(15.84)$ & $65.78(14.41)$ & $71.92(35.39)$ & $19.8 \%$ \\
\hline & Usual care & 117 & $36.83(10.45)$ & $48.83(10.05)$ & $78.38(13.77)$ & $62.87(12.52)$ & $73.47(32.41)$ & $12.8 \%$ \\
\hline \multirow[t]{2}{*}{12 weeks } & TEP & 109 & $40.99(11.60)$ & $52.80(9.73)$ & $78.43(15.36)$ & $65.76(14.48)$ & $72.71(34.14)$ & $11.9 \%$ \\
\hline & Usual care & 116 & $40.27(10.49)$ & $51.12(9.55)$ & $77.91(14.65)$ & $62.99(13.38)$ & $72.09(34.28)$ & $11.2 \%$ \\
\hline \multirow[t]{2}{*}{24 weeks } & TEP & 108 & $42.60(12.53)$ & $52.38(10.03)$ & $77.59(15.47)$ & $66.70(14.62)$ & $62.43(41.30)$ & $23.1 \%$ \\
\hline & Usual care & 102 & $41.57(11.46)$ & $51.14(9.34)$ & $74.02(16.23)$ & $64.89(15.41)$ & $75.34(32.41)$ & $16.7 \%$ \\
\hline
\end{tabular}

Table 5

Mean TEP Usual-Care Difference Paired Contrast, Adjusted for Covariates

\begin{tabular}{|c|c|c|c|c|c|c|c|c|c|}
\hline & \multirow{2}{*}{$\begin{array}{c}\text { SF-12 } \\
\text { physical } \\
\\
\text { Mean } \\
\text { difference* }^{*}\end{array}$} & \multirow[b]{2}{*}{$\underset{\substack{\text { Raw } \\
\text { probability } \\
\text { level }}}{\text {. }}$} & \multirow[b]{2}{*}{$\begin{array}{c}\text { Sidak } \\
\text { adjusted } \\
\text { probability } \\
\text { level }\end{array}$} & \multicolumn{2}{|l|}{ SF- 12 mental } & \multirow[b]{2}{*}{$\begin{array}{c}\text { Sidak } \\
\text { adjusted } \\
\text { probability } \\
\text { level }\end{array}$} & $\begin{array}{l}\text { SCHFI Self- } \\
\text { maintenance }\end{array}$ & \multirow[b]{2}{*}{$\underset{\substack{\text { Raw } \\
\text { levability }}}{\text { fevel }}$} & \multirow[b]{2}{*}{$\begin{array}{c}\text { Sidak } \\
\text { adjusted } \\
\text { probability } \\
\text { level }\end{array}$} \\
\hline & & & & $\begin{array}{c}\text { Mean } \\
\text { difference* }\end{array}$ & $\begin{array}{c}\text { Raw } \\
\text { probability } \\
\text { level }\end{array}$ & & $\begin{array}{c}\text { Mean } \\
\text { difference* }\end{array}$ & & \\
\hline 1 week & 2.398 & .020 & .097 & 2.506 & .027 & .127 & 1.093 & .508 & .971 \\
\hline 4 weeks & 2.686 & .014 & .070 & 1.676 & .152 & .563 & 1.493 & .378 & .907 \\
\hline 8 weeks & 2.016 & .094 & .390 & 4.192 & .001 & .001 & .933 & .437 & .943 \\
\hline 12 weeks & 0.691 & .758 & .999 & .764 & .447 & .948 & .942 & .535 & .978 \\
\hline \multirow[t]{3}{*}{24 weeks } & 1.260 & .528 & .977 & .567 & .530 & .977 & 4.115 & .030 & .143 \\
\hline & MILQ & & & $\begin{array}{c}\text { Satisfaction } \\
\text { with } \\
\text { nursing } \\
\text { care } \\
\end{array}$ & & & $\begin{array}{c}\text { Service } \\
\text { utilization }\end{array}$ & & \\
\hline & $\begin{array}{c}\text { Mean } \\
\text { difference* }^{*}\end{array}$ & $\begin{array}{c}\text { Raw } \\
\text { probability } \\
\text { level }\end{array}$ & $\begin{array}{c}\text { Sidak } \\
\text { adjusted } \\
\text { probability } \\
\text { level }\end{array}$ & $\begin{array}{c}\text { Mean } \\
\text { difference* }\end{array}$ & $\begin{array}{c}\text { Raw } \\
\text { probability } \\
\text { level }\end{array}$ & $\begin{array}{c}\text { Sidak } \\
\text { adjusted } \\
\text { probability } \\
\text { level }\end{array}$ & $\begin{array}{c}\text { Proportional } \\
\text { difference }\end{array}$ & $\begin{array}{c}\text { Raw } \\
\text { probability } \\
\text { level }\end{array}$ & $\begin{array}{c}\text { Sidak } \\
\text { adjusted } \\
\text { probability } \\
\text { Level }\end{array}$ \\
\hline 1 week & 1.929 & .145 & .542 & .784 & .581 & .987 & .009 & .667 & .996 \\
\hline 4 weeks & 1.269 & .303 & .836 & .820 & .589 & .988 & .070 & .124 & .485 \\
\hline 8 weeks & 1.085 & .209 & .690 & -.373 & .817 & $\sim 1.000$ & .072 & .123 & .480 \\
\hline 12 weeks & .892 & .329 & .864 & .557 & .735 & .999 & .003 & .971 & $\sim 1.000$ \\
\hline 24 weeks & -.281 & .862 & $\sim 1.000$ & -.047 & .979 & $\sim 1.000$ & .061 & .289 & .818 \\
\hline
\end{tabular}

*Untransformed mean differences

18 Flatey Brennan, Casper, Burke, Johnson, Brown, Valdez, Sebern, Perez \& Sturgeon 
Figure 1

Flow diagram of participant enrollment: modified version of CONSORT
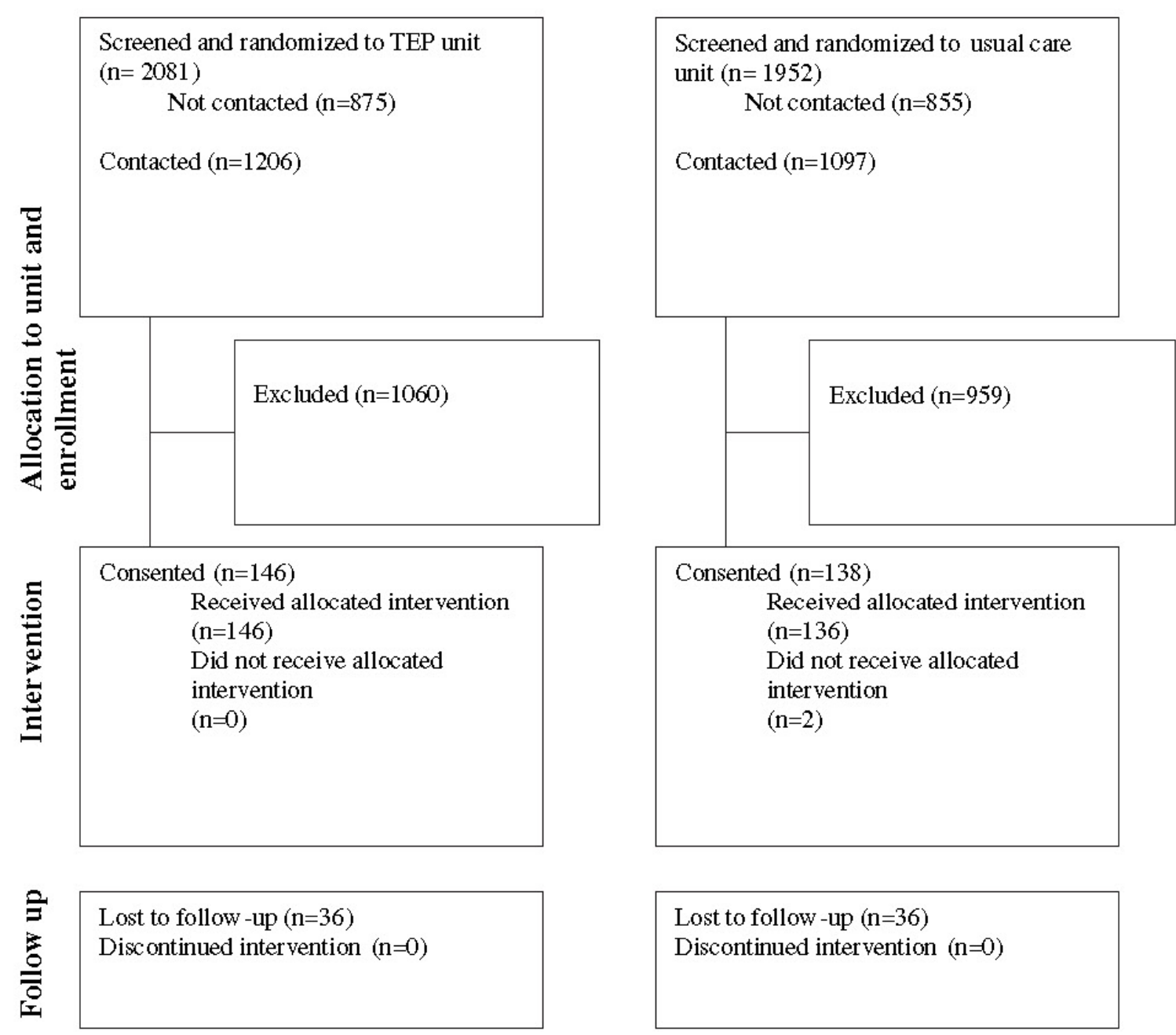

Lost to follow -up $(n=36)$

Discontinued intervention $(\mathrm{n}=0$ )

Analyzed $(\mathrm{n}=146)$

Analyzed $(\mathrm{n}=136)$

Excluded from analysis $(n=0)$

19 Flatey Brennan, Casper, Burke, Johnson, Brown, Valdez, Sebern, Perez \& Sturgeon 
Figure 2

Outcomes over time, using adjusted means
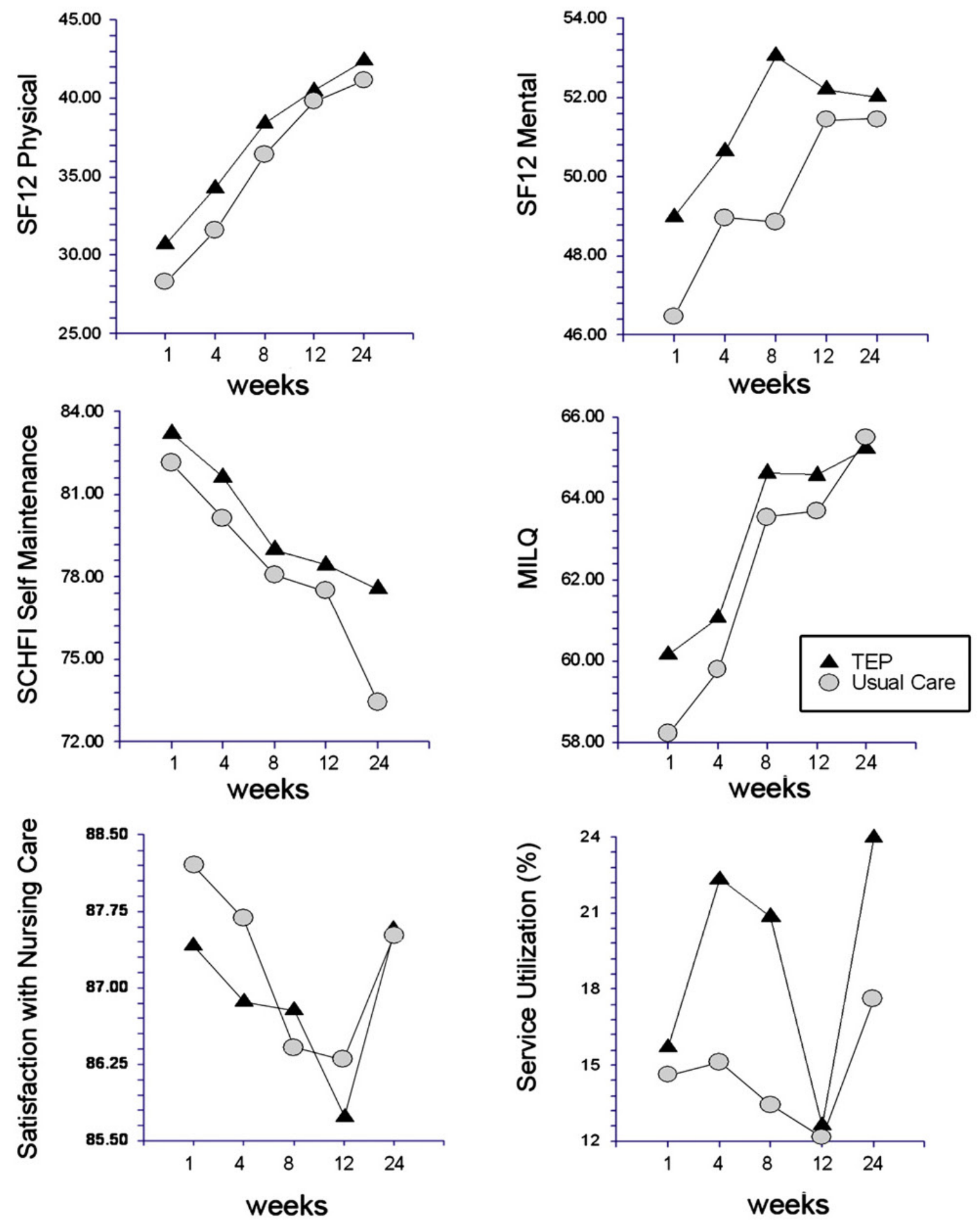

20 Flatey Brennan, Casper, Burke, Johnson, Brown, Valdez, Sebern, Perez \& Sturgeon 